University of Nebraska - Lincoln

DigitalCommons@University of Nebraska - Lincoln

Papers in Communication Studies

Communication Studies, Department of

$10-2010$

\title{
Transmitting Relational Worldviews: The Relationship between Mother-Daughter Memorable Messages and Adult Daughters' Romantic Relational Schemata
}

Jody Koenig Kellas

University of Nebraska-Lincoln, jkellas2@unl.edu

Follow this and additional works at: http://digitalcommons.unl.edu/commstudiespapers

Part of the Critical and Cultural Studies Commons, Gender, Race, Sexuality, and Ethnicity in Communication Commons, and the Other Communication Commons

Koenig Kellas, Jody, "Transmitting Relational Worldviews: The Relationship between Mother-Daughter Memorable Messages and Adult Daughters' Romantic Relational Schemata" (2010). Papers in Communication Studies. 110.

http://digitalcommons.unl.edu/commstudiespapers/110

This Article is brought to you for free and open access by the Communication Studies, Department of at DigitalCommons@University of Nebraska Lincoln. It has been accepted for inclusion in Papers in Communication Studies by an authorized administrator of DigitalCommons@University of Nebraska - Lincoln. 


\title{
Transmitting Relational Worldviews: The Relationship between Mother-Daughter Memorable Messages and Adult Daughters' Romantic Relational Schemata
}

\author{
Jody Koenig Kellas \\ Corresponding author - Jody Koenig Kellas, Department of Communication Studies, University of Nebraska-Lincoln, \\ 428 Oldfather Hall, Lincoln, NE 68588-0329, email jkellas2@unl.edu
}

\begin{abstract}
This study investigates memorable messages that daughters report hearing from their mothers about romantic relationships to examine the development of meaning in the content of parent-child communication and the ways in which these messages may affect and reflect adult daughters' relational worldviews. Findings from a study involving 149 adult daughters revealed 4 supra-categories of memorable messages: value self, characteristics of a good relationship, warnings, and value the sanctity of love. Moreover, statistical analyses reveal that memorable message types significantly related to daughter's romantic relationship schemata as operationalized by Fitzpatrick's (1988) couple types. Both message and couple type predicted intergenerational transmission.
\end{abstract}

Keywords: intergenerational transmission, family communication, memorable messages, motherdaughter communication, relational schemata

Research on family communication shows that the family is the first relational context in which we learn values and norms for interacting within and outside the family (Berger \& Luckman, 1966). One of the many ways this learning occurs is through the stories that parents pass on to children, often in the spirit of giving advice or teaching values (Stone, 2004). These lessons might be embraced or rejected, but whether positive or negative, the 
content of parent-child communication is often memorable and may have a lasting impression on children. These impressions are the subject of this investigation.

Research suggests that the socialization emergent in family communication may result in memorable messages about important life lessons (Honeycutt \& Cantrill, 2001). These messages are easily recalled, may shape individuals' evaluations of behavior, and can guide their feelings and actions (Knapp, Stohl, \& Reardon, 1981; Smith \& Ellis, 2001). Moreover, anecdotal evidence in research on memorable messages suggests that many of the messages people recall are about romantic relationships (e.g., "birds of a feather flock together," Honeycutt \& Cantrill, 2001, p. 37; see also Knapp et al., 1981). Despite existing research on memorable messages, little systematic investigation has examined how the content of parent-child communication socializes children to adult romantic relationships or how stories and messages help to shape how we make meaning about romantic relationships in adulthood.

This study focuses on the content of memorable messages between mothers and daughters, in particular. The mother-daughter relationship is both valorized and vilified, and its complexity along with its contextual ripeness for understanding the transmission of family messages makes it a fertile relationship for examining ideologies about relationships. Researchers have established that mother-child interaction is influential in developing both child and adult attachment styles (Bowlby, 1977) and is important to transmitting worldviews to daughters (Gordon, 1998; Orr, 2000). By examining the content of mothers' memorable messages, this investigation offers a communicative perspective on the development of meaning and provides one window into the socialization of daughters.

Although we know that memorable messages are reported to have lasting effects on their recipients, we know less about the manner in which they influence recipients in their thinking, feeling, and behavior in future interactions. Thus, a second purpose of this study is to better understand the ways in which mother-daughter communication is reported to affect and reflect a daughter's relational worldview about her current adult romantic relationship. Theories linking cognition and communication, such as schema theories, provide a useful frame for examining the lasting impact of family communication on daughters' adult relationships. Relational schemata are knowledge structures that help us remember, organize, and interpret information about relationships (Honeycutt \& Cantrill, 2001), and one of the most widely recognized typologies for conceptualizing romantic relational schemata is Fitzpatrick's (1988) couple types. In addition to the content of memorable messages, this study also investigates the extent to which recalled memorable messages relate to daughters' adult relational ideologies, or couple types, to offer a glimpse into the ways in which significant socializing messages affect and reflect our relational worldviews.

Finally, this study highlights the importance of intergenerational communication (Pecchioni, Wright, \& Nussbaum, 2005; Williams \& Nussbaum, 2001) by focusing not only on mother-daughter communication but also examining the ways in which memorable messages and schemata might predict the likelihood that the collection of memorable messages daughters receive from their mothers will get passed on to the next generation. In doing so, it offers an initial glimpse into the ways in which meaning might be transmitted across generations of women in families. In what follows, the research linking memorable messages, relational schema, and intergenerational transmission is reviewed before presenting 
a study of 149 women's memorable messages reportedly received from their mothers and the ways in which the content of these messages relates to relational constructs in adulthood.

\section{The Intergenerational Transmission of Meaning}

A growing body of research focuses on intergenerational family communication across the lifespan (e.g., Coupland \& Nussbaum, 1993; Williams \& Nussbaum, 2001), highlighting the importance of family communication on individuals' cognitive and behavioral development (Anderson \& Sabatelli, 2007; Pecchioni et al., 2005). Much of the research in this area focuses on the ways in which beliefs (e.g., stereotypes and paternalism) affect communication processes (e.g., under-accommodation and decision making; e.g., Cicirelli, 1993; Pecchioni \& Nussbaum, 2001; Williams \& Nussbaum, 2001). This study complements this research, looking instead at how the content of communication processes might affect beliefs. It does so by examining how memorable messages relate to daughters' ideologies about romantic relationships and subsequently may be transmitted to future generations.

\section{Memorable Messages}

A focus on the content of family communication and its lasting impact is well supported by a memorable messages framework. Memorable messages are recalled messages, typically passed down from respected and older others, such as parents, which have a lasting and significant impact on the lives of the hearer (Knapp et al., 1981). In their original investigation, Knapp et al. found that memorable messages last over time because they are personally involving, shared most often for the benefit and well-being of the recipient at a time when he or she might be particularly in need of help, and are brief and applicable across contexts. Memorable messages often take the form of a prescriptive command or injunction and may appear like proverbs, rules, or clichés. Despite the potential to be seen as cliché, individuals tend to view them as highly personally relevant and may adopt them because they come from people of higher status in private settings (Knapp et al., 1981). Memorable messages are often transmitted in family settings from parent to child and have lasting impact beyond the parent-child interaction.

Since Knapp et al.'s (1981) seminal work on memorable messages, other scholars have demonstrated memorable messages as significant for making sense of communication in a variety of other contexts, including socialization messages received by newcomers in organizations (Barge \& Schlueter, 2004; Dallimore, 2003), spirituality in final conversations (Keeley, 2004), and parental socialization of children via work-life messages (Medved, Brogan, McClanahan, Morris, \& Shepherd, 2006). Moreover, individuals recall both positive and negative memorable messages (e.g., Ford \& Ellis, 1998; Holladay, 2002), and research indicates that memorable messages help to create values in people that affect their interactions in future contexts. For example, Smith and Ellis (2001) found that memorable message type related to individuals' evaluations of their own actions and standards for acceptable behavior. These findings "highlight the importance of communication in establishing reference values in people" (Smith \& Ellis, 2001, p. 167) and suggest that memorable 
messages serve as lasting scripts, guides, or prescriptions, that both shape our actions and serve as measuring sticks for evaluating our behavior.

\section{Parent-Child Socialization Messages}

Given that memorable messages are most often received from older, respected adults, and parents often are seen as such, parent-child interaction is especially important in understanding how memorable message content shapes our worldviews. Medved et al. (2006), for example, argued that memorable messages are socializing tools used by parents to communicate meaning about the intersections of work and family life. They further argued that memorable messages offer a uniquely communicative lens to understanding family socialization processes and that "detailed attention needs to be paid to the critical messages and interactions shaping how we make sense out of our social worlds over the course of a lifetime" (p. 163). In their study, adult children were able to recall 928 memorable messages, suggesting that meaning about work-family life is transmitted from parent to child in ways that are significant for the child. They also examined sex differences and found that, when recalling messages about how to balance work and family, daughters received messages from their parents significantly more often than sons about stopping work once they had children and about choosing jobs that would be more likely to accommodate family life.

Medved et al.'s (2006) findings suggest that, in some cases, men and women receive different socialization messages from their parents. Similarly, Chance and Fiese (1999) found that mothers framed their stories of disappointment with emotion more often with daughters than with sons. Further, in her research on communication between grandmothers, mothers, and daughters, Miller-Day (2004) argued that women "co-author" one another's lives - that is, in communication with each other, female family members discursively construct their realities about life and relationships. Although not the only important socializing relationship, the gendered nature of storytelling and memorable messages may make the mother-daughter dyad particularly important in understanding the transmission of relational meaning.

\section{The Significance of Mother-Daughter Communication}

An abundance of research positions the mother-daughter relationship as central to understanding relational transmissions through communication. More specifically, research suggests that the mother-daughter relationship itself is developed through communication (Jordan, 1993; Miller-Day, 2004), is significantly important to the development of daughter identity (e.g., Gordon, 1998), can be deeply transformative (Gilligan \& Rogers, 1993), is significant across the lifespan (Cicirelli, 1993; Pecchioni \& Nussbaum, 2001), and is characterized by the transmission of values and relational worldviews that can be both beneficial and damaging (Gordon, 1998; Orr, 2000). Research also suggests that daughters and mothers are more likely than other family relationship dyads to discuss romantic relationships (e.g., Guerrero \& Afifi, 1995) and that daughters, and children in general, may spend more time with their mothers (Youniss \& Smollar, 1985), making the mother-daughter a central family relationship (Williams \& Nussbaum, 2001) and a context ripe for communication about a variety of topics, including romantic relationships. 
Not all mother-daughter communication is positive, however. Although much research discounts the negative consequences of mother-daughter socialization (e.g., Miller-Day, 2004), other scholarship warns that mothers can have a detrimental effect on their daughters' future romantic relationship possibilities. Gordon (1998), for example, described the parental alienation syndrome in which mothers try to turn daughters against their own fathers, and claimed that this "brainwashing" may establish lifelong problems for daughters' ability to create and sustain intimacy in adult romantic relationships.

Whether positive or negative, both mothers and daughters report the ability to summarize communication and relationship lessons in the form of identifiable and recurrent messages (Medved et al., 2006; Miller, 1992). In fact, although not the central focus of her investigation, Miller found that women in her study all identified recurrent phrases akin to memorable messages (e.g., "You can fall in love with a rich man as well as a poor one") that summarized the mother-daughter relationship in some way.

Despite the research to date on memorable messages and Medved et al.'s (2006) initial exploration of family socialization messages, "family communication scholars more often focus on how communication skills or styles are taught through interaction and less on the reproduction of particular meanings or values [italics added]" (p. 165). To better understand the ways in which mothers advise daughters about important life lessons, such as the establishment and maintenance of romantic relationships, as well as the meanings that emerge in the content of mother-daughter socialization communication, the following research question is posed:

RQ1: What types of memorable messages about romantic relationships do daughters report receiving from their mothers?

\section{Linking Messages to Relational Ideologies}

Given that they are memorable, mothers' messages might also help daughters to evaluate the state of daughters' current adult romantic relationships. Theories that link cognition and communication help to make the connection between the meanings derived from memorable messages and individuals' outlook on relationships. According to Honeycutt and Cantrill (2001), memorable messages, such as stories, "are important in providing a link between cognitive models of relational development and communicative behavior in terms of enduring messages that reflect core values" (p. 168); these scholars call for research on "how relational stories reflect people's expectations for the development or maintenance of their current personal relationships" and relational worldviews (p. 168). One way of conceiving of relational worldviews includes the ways in which individuals develop schemata (or expectations), knowledge structures, and mental creations of relationships in their communication with others.

Koerner and Fitzpatrick (2002) defined relational schemas as "broadly consist[ing] of interrelated pieces of declarative and procedural knowledge about relationships that reside in long-term memory" (p. 74). Theories of relational schema suggest that individuals operate relationally under cognitive representations of reality and that these representa- 
tions both affect and are affected by family communication. Decades of research have positioned Fitzpatrick's (1988) marital types as a primary way of understanding romantic relational schemata from a communication lens. Fitzpatrick's research on marital types suggests that couples can be differentiated according to their values about marriage, their communication styles, and the levels of happiness they get from their marriages; and that these ideologies predict a number of individual and behavioral dimensions, such as power, conflict, and marital satisfaction (see also Fitzpatrick \& Caughlin, 2002). She distinguished three primary types of couples, including traditionals, independents, and separates. Traditional couples value time together, deep disclosure, conventional gender roles, selective conflict over important issues, and report happiness in their relationships. Independents value the satisfaction that marriage brings to each individual; they espouse nontraditional gender roles, and willingly engage in conflict with one another about a variety of topics. These couples report being relatively happy in their marriages. Separates also report happiness, but to a lesser degree, and conduct their marriages based on separate identities. They value traditional gender roles, avoid conflict, and lead independent lives from one another. Research has shown that romantic couples, such as engaged couples, demonstrate the ideologies associated with Fitzpatrick's marital types, such that the typology translates to nonmarital relationships (e.g., Honeycutt \& Wieman, 1999; Honeycutt, Woods, \& Fontenot, 1993; see also Fitzpatrick \& Ritchie, 1994). Moreover, the marital schemata that underlie couple types suggest an ideology about relationships that may serve as a measure of a daughter's relational worldview.

The ways in which these ideologies are formed and revised communicatively, however, have received less attention. We do know that marital types correspond in large part to family typologies, suggesting that family communication has an impact on relational schemata. In a study comparing the dimensions of marital and family schemata, Fitzpatrick and Ritchie (1994) found that traditional couples tended to head consensual families, or families who value both conformity and conversation. Independent couples, on the other hand, headed pluralistic families, encouraging openness, but focusing little on conformity. Fitzpatrick and Ritchie argued that "[independent] couples believe in egalitarianism in male and female roles and may try to convey these values to their children" (p. 296). In contrast, separates, who tend to head protective families, may not try to instill values in their children about life outside the family. These findings suggest that ideology may be socialized through communication in the family. One way this might occur between mothers and daughters is through the communication of memorable messages. Indeed, relational schemata according to Koerner and Fitzpatrick (2002), "[i]nvolves either direct experiences in the relationships for which schemas develop, or communication about these relationships [such as ... by learning about romantic relationships from others [italics added]" (p. 78). The content of this kind of communication, however, has received decidedly less attention despite researchers who position mother-daughter communication as key to developing relational ideologies (e.g., Gordon, 1998; Orr, 2000).

Research that has found links between couple types and conversational content, suggests that "implicit aspects of relationship definition are reflected ... in the content of discussion themes ..." (Sillars, Burggraf, Yost, \& Zietlow, 1992, p. 124). Moreover, the 
literature on memorable messages grounds the importance of message content and its abilities to shape our identities, as well as our ability to frame the experiences of our lives in both productive and unproductive ways. This study builds on this work and investigates the ways in which the message content daughters remember hearing from their mothers may shape and be shaped by their ideologies about romantic relationships. To examine this link, the following research question is proposed:

RQ2: How do daughters' relational schemata (i.e., couple type) differ based on the collection of memorable messages they report receiving from their mothers?

\section{Transmitting Meaning across Generations}

Finally, based on the theoretical grounding that values and lessons are transmitted across generations via stories and messages, this study is concerned with the extent to which certain memorable messages are more likely to be passed on to the next generation. Stone (2004) noted that, although some stories disappear, others last across several generations of a family. These lasting stories are told and retold presumably because they reinforce individual and family identity in productive ways (Stone, 2004; see also Nussbaum \& Bettini, 1994). These principles likely translate to the intergenerational transmission of memorable messages between mother and daughters. Specifically, relational schemata might have an impact on the likelihood of intergenerational transmission, such that if the memorable messages daughters recall complement their current relational worldviews, they may be more likely to pass them on to future generations. For example, a daughter may recall her mother's cautionary tales about avoiding conflict through the message, "Don't rock the boat in relationships." If the daughter identifies with a traditional relationship schemata and recalls her mothers' warnings, which are consistent with a traditional ideology, she might be more likely to pass the message on than a daughter with an independent schemata, who values the freedom of expressiveness and conflict in a relationship. To test these assumptions, and the types of messages that might be more likely to be transmitted, the following research question is posed:

RQ3: Does the reported likelihood of passing down a collection of mother memorable messages to the next generation vary as a function of memorable message type and relationship schemata?

Examining the likelihood of transmitting memorable messages to the next generation enhances current examinations of intergenerational communication (Anderson \& Sabatelli, 2007; Williams \& Nussbaum, 2001) and answers the call of researchers interested in how meaning is communicatively produced and reproduced in the family (Medved et al., 2006). 


\section{Method}

\section{Participants}

Participants in the study were 149 young adult daughters who reported that they were currently involved in a romantic relationship and who were willing to provide information on memorable messages they recalled receiving from their mothers. The women ranged in age from 15 to $49(M=21.56, S D=4.43) ; 140$ participants $(94 \%)$ identified themselves as White, 5 as Asian, and 1 person each identified herself as Black, Hispanic, Pacific Islander, or Native American. Of the 149 participants, 145 reported on messages from mothers who were still living and who ranged in age from 39 to $82(M=49.64, S D=5.76)$. Most of the women $(n=137)$ did not yet have children of their own. In terms of their current romantic relationships, on average, participants had been involved in serious romantic relationships $(M=5.90$ on a 7-point scale, $S D=1.25)$ for 27.23 months $(M d n=18.00, S D=36.34)$, and most reported on nonmarital romantic relationships $(n=125)$.

\section{Procedures}

After obtaining human subjects approval, women were recruited to participate in the study in one of two ways. First, female students were recruited from communication courses at a large university. Second, participants were recruited via snowball and network sampling. In exchange for completing the survey, student participants $(n=144)$ received extra credit for their participation, as well as $\$ 10$. Participants recruited outside the university $(n=5)$ received $\$ 10$. Data were collected via open- and closed-ended questionnaire items. Open-ended questions were used to gather rich descriptions of daughter's recalled memorable messages and stories. Closed-ended questions were used to measure daughters' relational schemata (couple types), the likelihood of intergenerational transmission, and a number of other variables not pertinent to this study.

\section{Memorable messages}

To complete the open-ended portion of the survey, daughters were asked to write down any memorable messages they could recall their mothers giving to them about romantic relationships and love that had had a lasting impression on them ("stuck with you") in some way. The instructions gave daughters a few examples (e.g., "You can't hurry love" and "Play the field") to illustrate what was meant by a memorable message, but they were instructed explicitly that these examples should not influence or limit their own message reports. Daughters were also instructed that remembering a memorable message did not mean that they necessarily took their mothers' advice and that these impressions could be positive, negative, or neutral.

To answer RQ1, daughters were asked to recall as many memorable messages as possible. The questionnaire allotted space to include up to three messages, with the option of getting additional paper if needed. No participants requested additional space, and participants reported between one and three memorable messages. Overall, 149 participants reported at least one memorable message, 134 reported on at least two memorable messages, and 70 reported on a total of three memorable messages $(M=2.37, S D=0.66)$. 


\section{Measures}

Likelihood of intergenerational transmission

To measure the likelihood of intergenerational transmission, after each memorable message participants were asked to rate on a 7-point Likert-type scale the likelihood of passing the messages on to their own daughters (real or hypothetical; i.e., "If you have/had a daughter, would you/did you pass this message on to your daughter?"). Higher scores reflected a higher likelihood of passing the message along. In general, daughters in the sample reported that they were very likely to pass them on to the next generation $(M=$ $6.08, S D=1.24)$.

\section{Relational schemata}

Current relational schemata was assessed using a measure adapted from Honeycutt et al. (1993) and subsequently used by Dainton and Stafford (2000). This method involves participants reading paragraph descriptions associated with traditional, independent, and separate relationship schemata and selecting the one that best describes their ideologies about romantic relationships. The descriptions ${ }^{1}$ were adapted in this study to focus on romantic relationships, generally, rather than marriage. Like Honeycutt et al., this method of measuring relational schemata was used rather than the more typically administered 77item Relational Dimensions Instrument (Fitzpatrick, 1988) to avoid participant exhaustion that may have resulted from the collection of both open-ended and closed-ended items on the survey. Over one half of the sample reported an independent relationship ideology ( $n$ $=93 ; 62.4 \%$ ). Fifty-five (36.9\%) participants identified with a traditional ideology, and only 1 participant identified with a separate ideology. Because of the inability of the separate couple type to generate variance within the sample, this participant was removed all statistical analyses.

\section{Coding}

Once the data were collected, the open-ended memorable messages were inductively coded (Bulmer, 1979). Specifically, two researchers - the author and a graduate studenteach separately read $50 \%$ of the data and generated thematic categories represented in the open-ended responses. The coders then met and compared themes, noting similarities and differences and refining the categories into a coherent set of types. Next, they used the new set of categories to reread the data separately, comparing the emergence of any new themes to those created in the first rounds of coding (Strauss \& Corbin, 1998). Finally, they met again to engage in negative case analysis (seeking evidence in the data that might contradict the existing themes; Bulmer, 1979).

Upon completion of this process, a final coding scheme was created that consisted of 4 supratypes and 14 subtypes of mother-daughter memorable messages (see the Results section). Next, two independent coders, unaware of the study's research questions, were trained extensively on the supratypes and subtypes of messages. Once proficient in the coding procedures, each hired assistant coded $100 \%$ of the data. Reliability analyses using Cohen's kappa revealed solid intercoder reliability for supratypes $(\kappa=.83)$ and subtypes 
$(\kappa=.81)$. Any discrepancies were discussed and resolved such that each message received one code for supratype and subtype.

\section{Results}

\section{$R Q 1$}

RQ1 asked about the content of memorable messages that daughters recalled hearing from their mothers about romantic relationships. Overall, daughters reported 333 memorable messages, and the findings of the inductive coding process revealed the existence of four supratypes of memorable messages, including "value the sanctity of love," "value self," "characteristics of a good relationship," and "warnings." Each supra-category was comprised of several subtypes. These supra- and subtypes are described later. Frequencies and examples are presented in Table 1.

\begin{tabular}{|c|c|c|}
\hline $\begin{array}{l}\text { Memorable Message } \\
\text { Supratypes and Subtypes }\end{array}$ & Frequency & Example \\
\hline Value self & $n=144$ & \\
\hline Value independence and time & $n=78$ & $\begin{array}{l}\text { You have your whole life to be married; experi- } \\
\text { ence different things and people first. } \\
\text { You are young; don't rush into anything. }\end{array}$ \\
\hline Value self-esteem and don't settle & $n=51$ & $\begin{array}{l}\text { There was always the idea of being patient and } \\
\text { not settling. We were always told that we } \\
\text { were amazing and we deserved the best. } \\
\text { You deserve the best. }\end{array}$ \\
\hline Progressive view on sex and relationships & $n=10$ & $\begin{array}{l}\text { You have to test drive the car before you } \\
\text { drive it (re: sex). }\end{array}$ \\
\hline More than "one" & $n=5$ & $\begin{array}{l}\text { There's more than one person out there for } \\
\text { everyone. }\end{array}$ \\
\hline Characteristics of a good relationship & $n=98$ & \\
\hline Qualities of a good man & $n=30$ & $\begin{array}{l}\text { Marry a rich man. } \\
\text { Give nerds a chance. }\end{array}$ \\
\hline Behavioral expectations & $n=26$ & $\begin{array}{l}\text { Be careful what you say-if you feel hurt or an- } \\
\text { gry, don't be confrontational about it. Take } \\
\text { time to settle down and be rational. } \\
\text { Be honest to the person you're with. }\end{array}$ \\
\hline Emotion and intimacy expectations & $n=24$ & $\begin{array}{l}\text { Marry your best friend. } \\
\text { Ask yourself is it really love or just attachment? } \\
\text { Be with someone who makes you happy. }\end{array}$ \\
\hline Homogamy & $n=11$ & $\begin{array}{l}\text { Find someone who has similar goals and } \\
\text { aspirations as you. }\end{array}$ \\
\hline Importance of extended family & $n=7$ & $\begin{array}{l}\text { Don't make him choose between his mom and } \\
\text { you; that's not fair. } \\
\text { When I get married, I not only will marry that } \\
\text { man, but also his family, so his family is } \\
\text { just as important as he is. }\end{array}$ \\
\hline
\end{tabular}




\begin{tabular}{|c|c|c|}
\hline Warnings & $n=57$ & \\
\hline General warnings & $n=47$ & $\begin{array}{l}\text { Don't let the good ones get away. } \\
\text { Don't ever trust boys. }\end{array}$ \\
\hline Stories of personal regret & $n=6$ & $\begin{array}{l}\text { My mother told me as a teenager that I did not } \\
\text { trust men and she told me it was because of } \\
\text { the way my father treated me. So, I believed } \\
\text { that the negative feelings I had towards } \\
\text { men and relationships were my father's } \\
\text { fault. } \\
\text { My mom told me that when she was my age } \\
\text { she didn't want to get married, but she did. }\end{array}$ \\
\hline Judgment/expectation for women or girls & $n=4$ & Unescorted girls are seen as prostitutes. \\
\hline Value the sanctity of love & $n=47$ & \\
\hline Virginity and moral obligations & $n=26$ & $\begin{array}{l}\text { Do not have sex before marriage. } \\
\text { Once you marry you stay together no matter } \\
\text { what. }\end{array}$ \\
\hline The "one" & $n=21$ & $\begin{array}{l}\text { You'll know when you find "the one." } \\
\text { If it is love and meant to be he will come back } \\
\text { to you. }\end{array}$ \\
\hline
\end{tabular}

Value self messages

Of the 333 memorable messages reported across the sample, the most frequently occurring type included messages about valuing the self $(n=144)$. These messages focused on daughters placing themselves, their goals, and their well-being above experiencing the benefits of romantic relationships and marriage. Four subtypes emerged within this category. Messages in the first subtype, labeled value independence and time, stressed the importance of daughters establishing and maintaining their individuality and taking their time before pursuing serious, committed relationships (i.e., marriage). These were messages in which mothers specifically encouraged their daughters to experience the world, go to college, establish a career, keep their own friends, and so forth. They also urged daughters to "play the field," date multiple people, and so forth before settling down; and discouraged daughters from rushing into committed relationships. These messages also often reflected feminist values associated with independence (e.g., "Don't let the man be the boss").

Value self-esteem and don't settle messages reflected a reinforcement of daughters as special, unique, important people. They highlighted the importance of daughters valuing themselves, their self-image, self-esteem (including mothers trying to enhance the daughter's self-esteem through encouragement), as well as the importance of not "settling" for a relationship that did not match or celebrate their individual worth. Ultimately, these were messages that appeared meant to reinforce a daughter's esteem and encourage her to value her own identity over that of a partner or relationship. The third subtype of the value self category, progressive view on sex and relationships, included messages that endorsed having sex before marriage, living together before marriage, and not needing to get married at all. Finally, more than "one" messages conveyed to daughters that there is more than one love out there for each person. These messages were often said to be shared to reassure daughters in light of past or current relational difficulties. 


\section{Characteristics of a good relationship messages}

The next most frequently occurring set of messages concerned the qualities of relationships that mothers encouraged their daughters to consider or act on in their romantic relationships, including things like communication practices, similarity, and love. These good relationship messages focused on the aspects of relationships, behaviors, and men that mothers most felt daughters should seek in a romantic relationship. Several subtypes emerged within this supra-category. The most frequently occurring of these subtypes was messages about the qualities of a good man. These were messages in which mothers reportedly discussed the positive qualities of men, types of men, and characteristics in a man that make him suitable for marriage (e.g., rich, handy, and "like your father").

Whereas messages about the qualities of men focused on the partner, messages about behavioral expectations focused on the behavior of the daughter or the couple necessary for making romantic relationships work. These messages were described as expressing the importance of communication, compromise, patience, honesty, hard work, and effort. Messages about emotion and intimacy expectations, on the other hand, encouraged the presence of emotions like happiness, humor, fun, and love, as well as intimacy, affection, and attachment ties, such as friendship and togetherness in relationships. Homogamy messages reportedly stressed the importance of similarity between partners, such as finding a partner with similar values. Finally, messages that invoked the importance of extended family were said to convey the importance of family ties, including both the relationships that will come with the romantic relationships (e.g., in-laws), as well as advice about how to treat extended family.

\section{Warnings}

The third most frequently occurring supratype of memorable messages included warnings to daughters about romantic relationships. These messages reportedly suggested that something negative would happen if daughters did not heed the advice or judgment embedded in their mothers' messages and were characterized by one of three subtypes. The first, general warnings, cautioned daughters about being careful in romantic relationships about any variety of things, such as avoiding choices that daughters might regret, as well as warnings about the negative characteristics of men in general. Stories of personal regret involved messages that daughters recalled mothers sharing about regret in her own life choices. Most of these messages revolved around regret about the mother's relationship with the daughter's father, whether the mother and father were still married or divorced. Finally, a few daughters reported that their mothers sent messages that cast judgment on them as girls or about females, in general. Thus, judgments and expectations for women or girls messages conveyed negative assessments of daughters' behaviors and expressed negatively valenced expectations of girls, in general.

Value the sanctity of love

Perhaps somewhat surprisingly, the least frequent supratype of messages reported in this sample were messages about valuing the sanctity of love. The subcategories under this supratype focus on the purity and sacredness of love and marriage, including establishing love and marriage ideals (or as "the" ideal). Some mothers reportedly communicated to 
their daughters messages about virginity and moral obligations. This category involved prescriptions about morality, including (a) maintaining one's virginity (not having sex before marriage) and (b) the sanctity of marriage (divorce is not an option). Finally, the "one" messages communicated to daughters the idea that when daughters find love they will "just know" because there is one person out there for them. These were messages that expressed that love is "meant to be." Overall, the results of RQ1 show that daughters recalled a variety of lessons, values, prescriptions, and cautions from their mothers about romantic relationships.

\section{$R Q 2$}

To test RQ2, and because participants reported an unequal number of memorable messages, message types were further coded to assess a holistic picture of the collection of memorable messages women reported hearing from their mothers. To do this, the author assigned each participant a code for the majority type of memorable messages they reported. If a woman only reported on one type of memorable message (e.g., value self), she was assigned a code for "value self." If she reported receiving three memorable messages and two were about self, and one was about warnings, she also received a code of "value self" because it represented the majority type in her collection of messages. Women whose reports reflected no majority received a code that indicated a "mixed" collection of messages. Thus, for RQ2 and RQ3, memorable message type is operationalized as the only or majority type indicated in her collection of message, and included five potential categories: value self $(n=45 ; 30.2 \%)$, value the sanctity of love $(n=10 ; 6.7 \%)$, characteristics of a good relationship ( $n=29 ; 19.5 \%)$, warnings $(n=14 ; 9.4 \%)$, or a mixed collection of messages $(n=50$; $33.6 \%)$.

To test differences between memorable message type and relational schemata, a twoway contingency table analysis using crosstabs was used, and revealed a significant relationship between messages and schemata: Pearson's $\chi^{2}(4, N=147)=10.93, p<.05$; Cramer's $V=.27$. Follow-up pairwise comparisons were conducted to assess the differences among groups. Table 2 illustrates the findings of these analyses. Using the Holm's sequential Bonferroni method for control of Type 1 error across all pairwise comparisons, results indicate that significant pairwise differences for schemata existed between daughters whose message type was about valuing self and those whose message types were about characteristics of a good relationship, warnings, or a mixed collection of messages. ${ }^{2}$ More specifically, daughters who received value-self messages were significantly more likely (4.62 times) to identify having an independent relationship schemata rather than a traditional one, whereas daughters who received the other messages types were equally likely to have traditional or independent schemata. Moreover, daughters with traditional schemata were much more likely (2.71 times) to receive a mixed collection of messages than they were to receive value self messages, and women with independent schemata were much more likely to receive value self messages than warnings. Thus, the results of RQ2 indicate that women who reportedly receive value self messages are much more likely to be independent in their relational worldview, and these women are particularly more likely to receive value self than warning messages. Traditional women, on the other hand, were much more 
likely to receive a mixed collection of messages than they were to receive value self messages.

\begin{tabular}{lccc}
\hline \multicolumn{1}{l}{ Table 2. Results for the Pairwise Comparisons Using Holm's Sequential Bonferroni Method } \\
\hline Comparison & $\chi^{2}$ & $p(\alpha)$ & Cramer's $V$ \\
\hline Self versus characteristics & 7.85 & $.005(.005)$ & .33 \\
Self versus mixed & 7.54 & $.006(.006)$ & .28 \\
Self versus warnings & 5.85 & $.016(n s)$ & .34 \\
Self versus love & 3.09 & $.080(n s)$ & .24 \\
Warnings versus mixed & 0.16 & $.690(n s)$ & .05 \\
Characteristics versus mixed & 0.14 & $.710(n s)$ & .04 \\
Love versus warnings & 0.07 & $.800(n s)$ & .05 \\
Love versus characteristics & 0.04 & $.840(n s)$ & .03 \\
Characteristics versus warnings & 0.01 & $.920(n s)$ & .02 \\
Love versus mixed & 0.00 & $.980(n s)$ & .00 \\
\hline
\end{tabular}

\section{$R Q 3$}

Finally, to test RQ3, which asked whether the likelihood of daughters passing messages on to the next generation varied as a function of schemata and message type, a $5 \times 2$ factorial analysis of variance was conducted. To enable comparison across participants who varied in the number of memorable messages reported, the average likelihood of transmission score was computed across the memorable messages provided by daughters. ${ }^{3}$ Means and standard deviations for likelihood of intergenerational transmission as a function of schemata and message type are reported in Table 3. Although there was no significant interaction $-F(4,134)=0.96$, ns (partial $\left.\eta^{2}=.03\right)$ - main effects were found for schemata, $F(1,134)$ $=7.90, p<.01$ (partial $\eta^{2}=.06$ ); and for memorable message type, $F(4,134)=2.51, p<.05$ (partial $\left.\eta^{2}=.07\right)$.

Table 3. Means and Standard Deviations for Likelihood of Intergenerational Transmission

\begin{tabular}{llcc}
\hline Schemata & Memorable Message Type & $M$ & $S D$ \\
\hline Traditional & Value the sanctity of love & 5.92 & 1.26 \\
& Value self & 6.13 & 1.44 \\
& Characteristics of a good relationship & 6.10 & 0.89 \\
& Warnings & 4.43 & 2.10 \\
& Mixed & 5.77 & 1.56 \\
\multirow{5}{*}{ Independent } & Total & 5.75 & 1.51 \\
& Value the sanctity of love & 7.00 & 0.00 \\
& Value self & 6.17 & 1.10 \\
& Characteristics of a good relationship & 6.48 & 0.58 \\
& Warnings & 5.90 & 1.76 \\
& Mixed & 6.31 & 0.83 \\
& & 6.29 & 1.00 \\
\hline
\end{tabular}


An examination of the means for schema indicates that daughters with independent schemata were more likely to report that they would pass on the messages they received to the next generation $(M=6.29, S D=1.00)$ than were daughters with traditional schemata $(M=5.75, S D=1.51)$. Follow-up tests using pairwise comparisons for memorable message type were conducted to assess which collection of message types was more likely to be passed on to the next generation. Across pairwise comparisons, Tukey's honestly significant difference (HSD) method was used to control for Type 1 error. The results of this analysis indicate that daughters were significantly less likely to report that they would pass on warnings than pass on messages about the characteristics of a good relationship ( $p=.037)$, value self messages $(p=.056)$, value the sanctity of love messages $(p=.067)$, and a mixed collection of messages $(p=.096)$. Thus, results of RQ3 indicate that daughters with traditional schemata and daughters who received warnings about the negative consequences of not heeding mothers' advice were significantly less likely to report that they would pass messages on to the next generation.

\section{Discussion}

This study sought to investigate the messages about romantic relationships that are passed down from mother to daughter. The findings indicate that daughters recall a variety of such messages, including messages about valuing the self, characteristics of a good relationship, valuing the sanctity of love, and warnings. These message types helped to distinguish between relationship schemata, suggesting a seldom-tested connection between the content of mother-daughter communication and daughters' relational worldviews. Further, message type also related to the likelihood of intergenerational transmission in ways that may benefit future research and practice in mother-daughter communication. These findings build on the projects of scholars interested in intergenerational communication (Pecchioni \& Nussbaum, 2001; Williams \& Nussbaum, 2001) and relational communication schemata (Fitzpatrick, 1988), but adds to this literature by focusing on the ways in which family communication processes may have an impact on ideologies in mother-daughter socialization. The discussion that follows highlights the findings and offers three overarching implications from this study.

To begin, daughters recall a wide range of memorable messages from their mothers about romantic relationships. Thus, the first implication of this study is the support provided for the claim that the mother-daughter relationship is a significant one in the socialization about romance, as well as for the transmission of meanings, lessons, and values (Miller-Day, 2004). Daughters' reports that they were highly likely to pass these messages on to the next generation further confirms this finding by demonstrating the ways in which messages may last over time.

In general, daughters reported a positive collection of messages. This is consistent with Knapp et al.'s (1981) findings that people tended to recall a majority of positive messages, as well as research that counters the lay notions of mother-daughter conflict (e.g., Pecchioni \& Nussbaum, 2001). Specifically, the most often reported type of memorable message across this sample involved messages about valuing the self. It may be that mothers tend to be particularly mindful of bolstering the self-esteem of their daughters; or that college 
students, who made up much of this sample, are particularly focused on independence and, thus, recall these messages more clearly. Research on emerging adulthood suggests that this period provides opportunities for identity reflection that might be unique to other periods across the lifespan (Luyckx, Soenens, Vansteenkiste, Goossens, \& Berzonsky, 2007). Moreover, because a majority of participants had attended or were attending college prior to marriage, participants may have received supplemental messages of support and encouragement about independence, which may have affected the types of messages they recalled. More important, however, findings suggest that in spite of media, lay, and research representations of a mother-daughter relationship wrought with tension (MillerDay, 2004), daughters reported on messages that can be viewed as positive, well-received, and supportive.

A second implication of this study resides in the finding that a daughter's collection of memorable messages from her mother helps to explain differences in her current ideologies about romantic relationships. These findings show that daughters with independent relational schemata were much more likely to report receiving messages about valuing the self than any other message type. Value self messages are consistent with independent relational ideologies that encourage autonomy and that may be fostered in families that promote expressiveness and nonconformity (Fitzpatrick \& Ritchie, 1994). Moreover, traditionals were less likely to recall receiving value self messages. This is arguably consonant with the ideology of interdependence, rather than independence, in traditional schemata. These findings therefore highlight, at least in a modest way, the relationship between communication content and the development of relationship worldviews. This speaks to a gap in current literature on intergenerational communication in general, and marital types specifically, which tends to focus more on the outcomes associated with schemata (see Fitzpatrick \& Cauglin, 2002) and less on the contributing factors. A focus on message content also provides a window into how communicated meanings may be interpreted across generations.

Although content is not the only feature important to understanding socialization, it has implications for future research and application. Because of their power to heal, hurt, teach, and discourage, an understanding of the content, intergenerational transmission, and impact of memorable messages is socially significant particularly because of the ethical implications it may have for parental communication. Indeed, Stone (2004) asserted, "our families begin to tell us their stories early in our childhoods when we're as blank and unresisting as we're ever going to be" (p. 10), suggesting that parental communication is both foundational and powerful. In this study, understanding how mothers' messages relate to children's relational schemata underscores the importance of family communication on daughters' meanings. It also corroborates Smith and Ellis's (2001) findings that memorable messages relate to individuals' reference values. The data in this study do not warrant a causal relationship, however. Thus, it may also be that a daughter's relationship schemata as related to her current romantic relationship shapes the types of messages she recalls her mother giving to her or that both constructs are influenced by some other variable.

Future research should test these possibilities and continue to investigate the relationship between message content and individual and relational outcomes that extend beyond 
the mother-daughter relationship. The collection of messages received from fathers, siblings, romantic partners, and trusted others also likely affect and reflect daughters' expectations for relationships. These expectations may in turn relate in patterned ways to individuals' experience of happiness in relationships. Future investigations of these links have important implications for family research and marital research, including parenting education (e.g., training on the impact of communicated messages between parent and child) and relational counseling (e.g., identifying the impact of messages on relational schemata and happiness).

A third implication from this study lies in the finding that certain messages are less likely to be passed on than others. In particular, daughters did not report plans to pass on messages that warned them about negative consequences or relayed negative information. Although this study's methodology did not measure memorable message valence, the coding of message categories suggests that all other message types were relatively positive in tone, whereas warnings tended to be negatively valenced. Thus, daughters in this sample seemed to enact a positivity bias in their ideologies about the stories and lessons they would share with their own daughters. This is consistent with research on the transmission of family stories that reinforce productive family identities (Stone, 2004). Another reason warnings might be less likely to be passed on involves messages about stories of personal regret. These were messages in which daughters recalled mothers lamenting their own choices, particularly with regard to the daughters' fathers. Gordon (1998) argued that mothers often "brainwash" their daughters against their fathers, which leads to a problem for daughters establishing healthy levels of intimacy across the lifespan. Based on this reasoning, post hoc analyses ${ }^{4}$ were conducted to test whether this subtype of memorable message was the least likely to get passed on. The findings suggest that daughters in this sample were significantly more likely to reject their mothers' stories of personal regret than almost every other subtype of message (see Table 4). An examination of open-ended responses suggested that most daughters disapproved of their mothers undermining their fathers or communicating regret. Negative family story frames have been associated with lower levels of family satisfaction and functioning (e.g., Koenig Kellas, 2005). Future research should test the relationship between such messages and daughter well-being to determine if there are implications for parental education about message content. 
Table 4. Means and Standard Deviations for Likelihood of Intergenerational Transmission by Memorable Message 1 Subtype

\begin{tabular}{lcc}
\hline Memorable Message Subtype & $M$ & $S D$ \\
\hline The “one" & 6.86 & 0.38 \\
Virginity and moral obligations & 5.79 & 1.97 \\
Value self-esteem and don't settle & 6.78 & 0.52 \\
Value independence and time & 6.20 & 1.35 \\
More than "one" & 6.50 & 0.71 \\
Emotional and intimacy expectations & 6.92 & 0.29 \\
Behavioral expectations & 6.86 & 0.38 \\
Homogamy & 5.67 & 1.15 \\
Qualities of a good man & 6.27 & 1.10 \\
Importance of extended family & 6.50 & 0.71 \\
General warnings & 5.65 & 1.77 \\
Judgment of daughter or girls & 1.50 & 0.71 \\
Personal stories of regret & 2.00 & 1.73 \\
\hline
\end{tabular}

Despite the fruitful nature of the findings, this study is not without its limitations. First, this sample consisted of primarily White college students, which may help to explain the prevalence of those who reported independent schemata. An investigation into how memorable messages differ based on culture and diversity in age would further our understanding of the link between message content and relational worldviews. A second limitation of this study was the inability to discriminate messages of daughters with separate relationship schemata. Separates, a couple type that might not develop until later in marriage, likely would report receiving a different set of memorable messages making their inclusion in future studies an important contribution to these findings. Third, this study only measured memorable messages and relational schemata from the daughter's perspective. Future research should examine the possible discrepancy between mothers' and daughters' recollection of mothers' messages, as this might speak to the effectiveness of particular message types. Finally, given the somewhat small effect size for schemata and reported message type as they related to the likelihood of intergenerational transmission, future research should examine the other factors associated with how and why messages get passed down from one generation to the next.

This study offers an initial glimpse into the meanings, worldviews, and transmissions associated with mother-daughter communication about romantic relationships. Given the links between family communication and individuals' psychological and physical health, the stories and messages that are transmitted in families merit further investigation. The impressions these messages make on future generations possess the potential to become important imprints on individual and family meaning.

Acknowledgments - Jody Koenig Kellas (Ph.D., University of Washington, 2002) is an associate professor in the Department of Communication Studies at the University of Nebraska-Lincoln. This research was supported by a University of Nebraska-Lincoln's Research Council Grant-in-Aid Award funded through a gift from the Jane Robertson Layman Fund. A previous version of this 
manuscript was presented to the Interpersonal Communication Interest Group at the Western States Communication Association annual meeting in Denver, Colorado, February 2008 and received a Top Four Paper Award. I thank Erin Willer for her instrumental assistance on the manuscript, particularly her assistance in developing the inductive coding scheme. I also thank Beth Ribarsky and Elissa Arterburn for their help in coding the data.

\section{Notes}

1. The following are descriptions of couple types (directly adapted from Honeycutt, Woods, \& Fontenot, 1993):

Type 1: You believe that your romantic relationship is very important and that you should sacrifice some personal independence for the relationship. You believe in stability and stress the importance of being able to predict your partner and your life together. You spend a lot of time with your partner, avoid conflict in general and may argue only over very important issues. You actually disclose more positive than negative feelings/matters that are hardly risky to reveal. You and your partner present yourselves as a couple to others and downplay distinct individual traits, habits, or skills. You believe you are highly interdependent in your relationship with your partner. You may engage in conflicts with your partner when the issues are serious ones.

Type 2: You believe that a romantic relationship exists for the gratification that the relationship gives to partners and that relationships should be based on the satisfaction that each partner gets from the relationship. You believe that in this quickly changing world it is vital that each individual have a strong sense of self that is not lost just because that person is in a committed romantic relationship. You do not keep regular daily schedules with your partner and have outside friends and interests. You disclose both positive and negative feelings to your partner. You are not afraid to openly express your views, are likely to engage in conflict, bargaining, and negotiation. You may agree to disagree. You hold what some may consider non-conventional views about romantic relationships. You are moderately interdependent with your partner and willingly engage in conflicts whether or not the issues are serious ones.

Type 3: In your romantic relationship, togetherness is a matter of habit and convenience. You believe your relationship is stable, yet includes little sharing of time together. The major points of contact occur at mealtimes or other regularly scheduled daily events. You go to great lengths to avoid conflict. You have a sense of duty and obligations connected with being a boyfriend/husband or girlfriend/wife. Although you tend to avoid conflict, you may sometimes confront your partner and take a verbal "pot shot" at the other. You feel you cannot express your innermost thoughts to your partner. You are careful in conversations with your partner, tend not to interrupt each other, and generally don't talk very much to your partner. You see romantic relationships and/or marriage as the product of factors that are outside your control, factors that are part of normal stages of life. (p. 303)

2. Although Holm's sequential Bonferroni method did not find a significant difference when adjusting for family-wise error on schemata between women who received value self messages and those who received warnings, estimates of effect size (Cramer's $V=.34$ ) for this difference suggest an important relationship, as well as a trend that parallels the other two significant findings presented in the results for Message $\times$ Schemata Type.

3. The likelihood of transmission variable was able to be collapsed across the individual memorable messages because within-subjects tests of difference showed no significant difference in the 
likelihood of intergenerational transmission across message types within individuals: individuals with three memorable messages, $F(2,134)=0.02$, ns; and individuals with two memorable messages, $t(60)=1.65, n s$. Thus, looking at the collection of memorable messages, along with the average likelihood of transmission within these collections of messages, was appropriate for testing RQ3.

4. Because all daughters recalled at least one memorable message, the first memorable message was used in the post hoc analysis. Thus, a one-way analysis of variance was run with Memorable Message 1 subtype as the independent variable and likelihood of intergenerational transmission of this message as the dependent variable. Findings of this analysis indicate that there was a significant difference between message subtype and likelihood of passing it on, $F(12,129)=6.85$, $p<.001$; and post hoc tests using Tukey's honestly significant difference test show that in all but one case (for the judgment of girls subtype), personal regret subtype messages were significantly less likely to be passed on than any other subtype. All means and standard deviations are presented in Table 4.

\section{References}

Anderson, S. A., \& Sabatelli, R. M. (2007). Family interaction: A multigenerational developmental perspective (4th ed.). Boston: Pearson.

Barge, J. K., \& Schlueter, D. W. (2004). Memorable messages and newcomer socialization. Western Journal of Communication, 68, 233-256.

Berger, P. L., \& Luckman, T. (1966). The social construction of reality: A treatise in the sociology of knowledge. Garden City, NY: Doubleday.

Bowlby, J. (1977). The making and breaking of affectional bonds. British Journal of Psychiatry, 130, 201-210.

Bulmer, M. (1979). Concepts in the analysis of qualitative data. Sociological Review, 27, 651-677.

Chance, C., \& Fiese, B. H. (1999). Gender-stereotyped lessons about emotion in family narratives. Narrative Inquiry, 9, 243-255.

Cicirelli, V. G. (1993). Intergenerational communication in the mother-daughter dyad regarding caregiving decisions. In N. Coupland \& J. F. Nussbaum (Eds.), Discourse and lifespan identity (pp. 215236). Newbury Park, CA: Sage.

Coupland, N., \& Nussbaum, J. F. (Eds.). (1993). Discourse and lifespan identity. Newbury Park, CA: Sage.

Dainton, M., \& Stafford, L. M. (2000). Predicting maintenance enactment from relational schemata, spousal behavior, and relational characteristics. Communication Research Reports, 17, 171-180.

Dallimore, E. J. (2003). Memorable messages as discursive formations: The gendered socialization of new university faculty. Women's Studies in Communication, 26, 214-265.

Fitzpatrick, M. A. (1988). Between husbands and wives. Newbury Park, CA: Sage.

Fitzpatrick, M. A., \& Caughlin, J. P. (2002). Interpersonal communication in family relationships. In M. L. Knapp \& J. A. Daly (Eds.), Handbook of interpersonal communication (3rd ed., pp. 726-777). Thousand Oaks, CA: Sage.

Fitzpatrick, M. A., \& Ritchie, L. D. (1994). Communication schemata within the family: Multiple perspectives on family interaction. Human Communication Research, 20, 275-301.

Ford, L. A., \& Ellis, B. H. (1998). A preliminary analysis of memorable support and nonsupport messages received by nurses in acute care settings. Health Communication, 10, 37-63. 
Gilligan, C., \& Rogers, A. (1993). Reframing daughtering and mothering: A paradigm shift in psychology. In J. van Mens-Verhulst, J. Schreurs, \& L. Woertman (Eds.), Daughtering and mothering: Female subjectivity reanalyzed (pp. 125-134). New York: Routledge.

Gordon, R. M. (1998). The Medea complex and the parental alienation syndrome: When mothers damage their daughters' ability to love a man. In G. H. Fenchel (Ed.), The mother-daughter relationship: Echoes through time (pp. 207-225). Northvale, NJ: Jason Aronson.

Guerrero, L. K., \& Afifi, W. A. (1995). Some things are better left unsaid: Topic avoidance in family relationships. Communication Quarterly, 43, 276-296.

Holladay, S. J. (2002). "Have fun while you can," "You're only as old as you feel," and "Don't ever get old!": An examination of memorable messages about aging. Journal of Communication, 52, 681697.

Honeycutt, J. M., \& Cantrill, J. G. (2001). Cognition, communication, and romantic relationships. Mahwah, NJ: Lawrence Erlbaum Associates, Inc.

Honeycutt, J. M., \& Weiman, J. M. (1999). Analysis of functions of talk and reports of imagined interactions (IIs) during engagement and marriage. Human Communication Research, 25, 399-419.

Honeycutt, J. M., Woods, B. L., \& Fontenot, K. (1993). The endorsement of communication conflict rules as a function of engagement, marriage, and marital ideology. Journal of Social and Personal Relationships, 10, 285-304.

Jordan, J. (1993). The relational self: A model of women's development. In J. van Mens-Verhulst, J. Schreurs \& L. Woertman (Eds.), Daughtering and mothering: Female subjectivity reanalyzed (pp. 135144). New York: Routledge.

Keeley, M. P. (2004). Final conversations: Survivors' memorable messages concerning religious faith and spirituality. Health Communication, 16, 87-104.

Knapp, M. L., Stohl, C., \& Reardon, K. K. (1981). "Memorable" messages. Journal of Communication, 31, 27-41.

Koenig Kellas, J. (2005). Family ties: Communicating identity through jointly told stories. Communication Monographs, 72, 365-389.

Koerner, A. F., \& Fitzpatrick, M. A. (2002). Toward a theory of family communication. Communication Theory, 12, 70-91.

Luyckx, K., Soenens, B., Vansteenkiste, M., Goossens, L., \& Berzonsky, M. D. (2007). Parental psychological control and dimensions of identity formation in emerging adulthood. Journal of Family Psychology, 21, 546-550.

Medved, C. E., Brogan, S. M., McClanahan, A. M., Morris, J. F., \& Shepherd, G. J. (2006). Family and work socializing communication: Messages, gender, and ideological implications. Journal of Family Communication, 6, 161-180.

Miller, M. (1992). The mother-daughter relationship: Narrative as a path to understanding. Women's Studies in Communication, 15, 1-21.

Miller-Day, M. A. (2004). Communication among grandmothers, mothers, and adult daughters: A qualitative study of maternal relationships. Mahwah, NJ: Lawrence Erlbaum Associates, Inc.

Nussbaum, J. F., \& Bettini, L. M. (1994). Shared stories of the grandparent-grandchild relationship. International Journal of Aging and Human Development, 39, 67-80.

Orr, D. (2000). Mothers as moral educators: Teaching language and nurturing souls. In A. O'Reilly \& S. Abbey (Eds.), Mothers and daughters: Connection, empowerment, and transformation (pp. 161174). Lanham, MD: Rowman \& Littlefield. 
Pecchioni, L. L., \& Nussbaum, J. F. (2001). Mother-adult daughter discussions of caregiving prior to dependency: Exploring conflicts among European-American women. Journal of Family Communication, 1, 133-150.

Pecchioni, L. L., Wright, K. B., \& Nussbaum, J. F. (2005). Life-span communication. Mahwah, NJ: Lawrence Erlbaum Associates, Inc.

Sillars, A. L., Burggraf, C. S., Yost, S., \& Zietlow, P. H. (1992). Conversational themes and marital relationships definitions. Human Communication Research, 19, 124-154.

Smith, S. W., \& Ellis, J. B. (2001). Memorable messages as guides to self-assessment of behavior: An initial investigation. Communication Monographs, 68, 154-168.

Stone, E. (2004). Black sheep and kissing cousins: How our family stories shape us. New Brunswick, NJ: Transaction.

Strauss, A., \& Corbin, J. (1998). Basics of qualitative research: Techniques and procedures for developing grounded theory. Thousand Oaks, CA: Sage.

Williams, A., \& Nussbaum, J. F. (2001). Intergenerational communication across the lifespan. Mahwah, NJ: Lawrence Erlbaum Associates, Inc.

Youniss, J., \& Smollar, J. (1985). Adolescent relations with mothers, fathers, and friends. Chicago: University of Chicago Press. 